\title{
9. Institutional co-innovation in value chain development: a comparative study of agro-export products in Uganda and Peru
}

\author{
A.H.J. Helmsing ${ }^{*}$ and W. Enzama \\ Erasmus University Rotterdam, International Institute of Social Studies, P.O. Box 29776, 2502 LT, The \\ Hague, the Netherlands; helmsing@iss.nl
}

\begin{abstract}
Institutional development has attracted more attention in the past two decades. However, institutional theory finds itself in a pre-consolidated phase and there are many theoretical and methodological challenges. One is to respond to the question whether institutional change is a spontaneous evolutionary or a deliberately designed process or a combination of the two. Another question concerns the interaction between technological innovations, changes in institutional arrangements and changes in the institutional environment in the dynamics of processes of institutional development. This links to another key question concerning the synchronicity in or co-evolution of institutional change processes at various levels and in various public and private domains. Institutional innovation rarely concerns one single institution but normally concerns bundles of public and private order institutions created at various levels. This paper researches how a common institutional need to develop institutional arrangements for rural collective action in order to enable small farmers to participate in newly created export chains, each with its own technological requirements and in different contexts leads to different institutional arrangements and outcomes. By comparing two cases, the paper seeks to unravel which factors and actors play what roles and how these explain differences in the process of institutional development and in that way to arrive at a better understanding of local institutional change. After a review of literature and the elaboration of a framework to answer the above questions, the paper presents a bird's eye views of the two case studies. The first refers to the introduction of new apicultural technologies in the North West of Uganda and the second relates to the introduction of high value horticulture exports crops in the North of Peru. The final section examines the main commonalities and differences in institutional development and makes an attempt to respond to the main questions formulated above.
\end{abstract}

Keywords: institutional development, co-innovation, collective action, value chains, developing countries 


\subsection{Introduction}

Since the late eighties, institutions have been recognised as playing an important role in economic development. It began with a critique of structural adjustment policies which centred too much on 'getting the prices' right, rather than on 'getting the institutions right'. Since the 1990s theorising about institutions has taken considerable leaps forward but still finds itself in a pre-consolidated stage and there are many theoretical and methodological challenges. Most attention has been given to influence of particular institutions on economic development and not on the reverse causality. Chang (2010) has made this point most effectively. Economic development also changes institutions as it gives rise to new agents and activities that demand new kinds of institutions; the wealth created in the process demands institutional change towards more accountability and transparency but also makes institutional change affordable.

A methodological challenge of comparative research in this regard is not to focus on an a-priori defined specific nominal institution but to focus on a common institutional need, which may give rise to distinct institutional solutions in distinct contextual settings (Maseland, 2011). In that way the interaction between institutions and economic development can better be captured. In this context, a key question is whether institutional change is one of deliberate design or a spontaneous evolutionary process (Kingston and Caballero, 2009) or a combination of these. The latter links to another key question, not raised by these authors, namely, concerning the synchronicity in or co-evolution of institutional change processes at various levels and in public and private domains. Institutional innovation rarely concerns one single institution but normally concerns bundles of public and private order institutions created at various levels. The literature often gives considerable attention to the State which is to provide an appropriate business institutional environment (i.e. set of institutions) within which economic agents and activity can prosper and within which private agents can develop their own complementary private order institutions. Is this necessarily a downward process where public institutions provide the framework within which private order institutions are created or adapted? Can the reverse also happen and if so, under what conditions? How do national and local level institutional change agents interact? Below we will give some conceptual elaborations necessary to answer these questions empirically.

We will then, in Section 9.2, give a bird's eye view of the two cases. The first concerns the introduction of new beekeeping technologies in the West Nile region of Uganda where a private company played a key role in creating an agro-export chain and non-governmental organisations (NGOs) a complementary one and the other case concerns the introduction of an agro-export crop in the Department of La Libertad in Northern Peru by a NGO with a private company as ally. The two cases constitute very different cultural and historical institutional settings (the state being more prominent in Uganda, than in Peru) but cover roughly the same period (2001-2008). In both instances the Government attempted to introduce market based agricultural business 
development services (BDS). The purpose of the analysis is not to identify a 'superior' institution to be replicated elsewhere but to get better insight in what complex set of factors and actors shape institutional change around a common institutional need.

The analysis of the two cases is structured using a time line. Necessarily, the presentation of the two cases will be sketchy and cannot be elaborated in all their richness for reasons of space. Section 9.3 concludes the paper and examines commonalities and differences between the two cases and contains some final observations concerning synchronicity in co-innovation processes.

\subsubsection{Understanding institutional change and co-evolution of institutional innovations}

Institutions are defined in a variety of ways in the literature. A common definition, states that institutions are rules of the game (see also Chang (2002). North (1990) maintained that institutions are humanly devised constraints that shape human interaction and Hodgson $(1988,2006)$ sees them as durable patterns of human interaction. Here we use the notion of rules, not as constraints but as rules that guide human behaviour. Nelson sees institutions as social technologies or 'ways of getting things done when human interaction is needed' (Nelson, 2008; Nelson and Sampat, 2001). Social technologies become institutions when they have become standard and the expected thing to do, given objective and setting (ibid., 2001: 40). The literature identifies different kinds of institutions. The most common distinction is between formal and informal institutions where the former are often associated with written rules. A partially overlapping distinction states that specialised actors or organisations (including judges and courts) enforce formal institutions (like laws). Informal ones are endogenously enforced by members of the associated group (Kingston and Caballero, 2009). Institutions may be voluntary and constitute a private order, while public institutions are normally apply to all citizens or functional groups within a designated jurisdiction or functional area.

Institutions tend to be nested and hierarchical. 'Nestedness' refers the fact that institutions are interrelated and that institutions at one level, set the stage for institutions at another level. For example, Williamson (2000) identifies four types of institutions where the time horizon of change is taken as a key criterion: (1) institutions of embeddedness, including informal institutions and norms, change in the order of centuries or millennia; (2) high level formal rules such as constitutions, laws and property rights normally change in the order of decades; (3) institutions of governance set the rules for day-to-day interactions and can be modified in the short run; finally; (4) transaction contracts, which set prices and quantities, change continuously. New institutional economists do not study type (1) institutions but take them for granted. They focus on level (2) and (3) institutions.

Embeddedness of institutions operates in two ways: it implies that for operational rules, higher level rules can be taken as given or as exogenous; but also that for 
changing operational rules it may be necessary to change also higher level rules. This is one of the causes of institutional path dependence or inertia (see below). The 'nestedness' also explains hierarchy between different kinds of institutions, but there is also hierarchy between rules of the same kind. The constitution takes precedence over any other law but also some laws take precedence over other laws (e.g. criminal over commercial law or children rights over employer rights). The hierarchy of rules is one of the important issues of struggle between groups who stand to gain or lose from particular rules (Chang, 2002).

One aspect of hierarchy concerns the scale at which an institution applies. Does it refer to all economic agents or to (self-)selected groups? Do agents have alternative options to deal with a similar institutional need? In some theoretical approaches the process by which the scale of institution rises, is called 'climbing the institutional ladder' (see below).

What drives institutions to change? North (2005) places emphasis on the advances of cognitive science or the ways in which we interpret the world and its problems. Hodgson (2006) and Gomez (2008) assume that an institutional gap emerges as a result of endogenous or exogenous shocks. That is to say, 'when action X does not result in expected outcome Y'. Other authors like Nelson (2002; Nelson and Sampat, 2001) see technology as the principal driver of institutional change. A new physical technology (i.e. new ways of producing, new products or new ways of undertaking activities) calls for a change in (internal) routines within the firm and may call for a change in ways of doing things between economic agents (institutions). Nelson thus stresses the importance of co-innovation (in technology, organisation, marketing, etc.) and by implication institutional innovations in various domains.

If we follow this reasoning then institutional change involves various actors. The literature puts emphasis on two categories of actors, from two different domains: one is the catalytic or institutional entrepreneur who acts on his/her own account or in association with other entrepreneurs who face similar institutional needs. They may form an association and pursue their institutional interests collectively. The second actor is the state. Some authors stress the 'embedded autonomy' of the state to design new institutions through deliberate economic policy (Evans, 1995). Conceptions of state vary, as does the emphasis on specific state actors and aspects of state functioning and performance. Some authors distinguish between roles of state bureaucrats and/or politicians in the institutional design process. With regard to late developing countries, we could add multilateral and bilateral aid agencies, which influence the direction of institutional change. Others stress the interaction between the public and the private domains. The State not only plays a role in terms of designing and enforcing public institutions but it also provides legitimacy to private order institutions. Economic interest groups struggle for power to control the state and in that way influence the direction of institutional change (Chang, 2002). 
New Institutional Economics (NIE) has made important contributions to the economic dimension of institutional change (Williamson, 1975, 2000). It is argued that under conditions of competitive markets durable institutional change occurs only when the new institution is efficient. Institutional options that result in fewer transaction cost reductions will eventually give way as being inefficient. At the micro level, NIE also points to the importance of asset specificities, information asymmetries, adverse selection and moral hazard problems, which trigger specific institutional designs. In many late developing countries markets are far from perfect; thin markets and market failures may be endemic and therefore such problems are far more frequent and as a result inefficient institutions may continue to abound.

As regards the sustainability of institutions, two perspectives tend to predominate. One emphasises the existence of competing institutional options and the voluntary nature of acceptance and replication. The instigator of a new rule may have to compensate others who may stand to lose from the new rule in order to prevent their opposition or their switching to another institutional alternative. The other stresses the role of the state and public enforcement of compliance. In this case the cost of enforcement is often not seen as an overriding consideration, as it remains hidden in overall cost of government but it does imply that administrative and public policy considerations may have considerable bearing on institutional design process. Bureaucrats may have a different view of the world than do entrepreneurs or politicians.

Institutional change is a path dependent process. Two important factors are situated bounded rationality of the actors and institutional inertia. Situated bounded rationality occurs, as learning and search processes are localised, time consuming and costly; as a result, information tends to be incomplete and processing capacity is limited. Actors therefore reveal satisficing behaviour. They will accept a 'good enough' institutional option. Risk aversion in situations of low trust and failing markets can further compound the selection process and prevent institutional change from becoming sustainable. North (2005) stressed the importance of mental models and ideologies with which actors work and which can influence the perceptions about the effects of alternative institutions. Institutional inertia can result due to the existence of free rider problems, which prevent collective action to change institutions. Furthermore, informal institutions can be an important source of institutional inertia. Last but not least institutional complementarities or interrelatedness can act as a severe brake on institutional change. Not only in functional terms but also because certain groups who benefit from the complementary institution can oppose the institutional change desired by others. In all, history or context plays an important role in the process of institutional change.

Brousseau and Raynaud (2007) have made an interesting contribution to the analysis of institutional change processes. They argue that institutional change begins as decentralised process of creating localised institutional orders. Local institutions tend to be voluntary as agents have always the option to create or join alternative institutional solutions to their common coordination need. Local institutional 
orders are therefore in competition with each other. They argue that at the local level economic competition takes place between different and alternative institutional options but at higher and more centralised level political competition between higher order institutions takes precedence. Their central contention is that local institutional arrangements have a built in tendency to seek to expand and 'climb the institutional ladder' and 'like lava, have the tendency to spread out and then solidify to become part of the institutional framework. When competing, agents can deploy different strategies. They can adapt and improve the quality of the institution so as to improve its efficiency and relevance to others; poach of go-betweens (that is, agents that ascribe to a rival institutional order but with coordination needs that are close to one's own); manipulate switching costs, by making it less attractive for existing members to defect; retaliate ex-post and ostracise defectors; and lastly, negotiate a merger (Brousseau and Raynaud, ibid.). Timing and 'first mover' advantages thus play an important role in the process of institutional change.

The nature of the relationships between public and private actors constitutes a key aspect in the synchronisation of institutional change processes. Do higher public order institutions (have to) precede the creation of private order institutions? Alternatively, do private order institutions 'climb the institutional ladder' as Brousseau and Raynaud suggest and/or demand or give rise to required complementary new public institutions, as Chang argues? Or do these two public and private institutional innovation processes take place simultaneously? Is the synchrony a matter of deliberate coordination between levels and domains or is it a matter of chance as their respective path dependent processes co-evolve?

We began with two main questions: Can institutional change best be seen as spontaneous rather than an outcome of deliberate design or as a combination of these two; and, if institutional change is about a complex set of institutions co-evolving at different levels and in different domains, what influences the co-innovation of institutions? We have elaborated above concepts that can help us answer these questions empirically.

\subsection{Bird's eye views of two case studies}

\subsubsection{Introduction}

The two case studies have been monitored over a period of time and the analysis is based on multiple site visits. In both cases both chain actors (including small farmer groups) and chain promoters have been interviewed.

\subsubsection{Institutional arrangements for beekeeping in West Nile, Uganda}

In the 1970s and early 1980s Uganda suffered from considerable political turmoil and economic mismanagement but with the National Resistance Movement (NRM) 
of Museveni taking control, the economy rebounded and political stability improved. The average annual rate of growth in the nineties was $6 \%$. The population below the poverty line declined from 56\% in 1992 to $38 \%$ in 2003. But in Northern Uganda unrest was not contained and the Lord's Resistance Army (LRA) and the Uganda National Rescue Front (UNRF II) in West Nile continued to create havoc. Only in 2002 the Government signed a peace treaty with UNRF II rebel groups and post-war reconstruction began in West Nile.

In 2000 the Government of Uganda launched an ambitious new Policy for the Modernization of Agriculture (PMA) to enhance production, competitiveness and incomes. One of the seven pillars of the reform was the delivery of agricultural extension through a new National Agricultural Advisory Services (NAADS). NAADS is considered to be an innovative public-private extension service delivery approach with the aim to increase commercial farming among Uganda's subsistence smallholders. This program was officially launched in 2001 to promote the development of farmer organisations and empower them to (1) procure advisory services; (2) to manage linkages with marketing partners and (3) to conduct demand driven monitoring and evaluation of advisory services and their impacts.

Under the NAADS policy, farmers can form groups, negotiate with private sector (NGOs) service providers, and award short-term contracts to promote specific farm enterprises and provide advisory services (Benin, 2007). NAADS implements and manages its program at the sub-county (LC3) level. At this level, priority farm products are identified and NAADS manages from here the allocation of contracts, monitors and evaluates performance and accountability of service providers and farmer groups. At LC3 level farmer forums are established, composed of representatives of farmer groups, which themselves operate at village level (LC1). The farmer groups are the basic unit receiving the advisory services. Members are selected from among the economically active poor (i.e. neither the destitute poor nor larger scale farmers). They are encouraged to work together around a particular crop or farm enterprise. The farmer groups are given advice on how to organise themselves and engage in collective action (e.g. learning how to set themselves up as a farmer group with a constitution and how to make bye-laws, etc.), engage the local government and service providers, manage technical development sites and organise demonstration and training sessions.

Arua District in West Nile (Northern Uganda) was one of the six 'trail blazing' districts in which the NAADS program was initiated in 2001. It was rolled out in 24 sub-counties of these six districts. In 2002/2003 the program was extended to 10 additional districts and in 2003/2004 and 2004/2005 another 13 districts were incorporated. In 2005 NAADS was active in 29 (of the then total of 70) districts and 280 sub-counties with some 13,200 operating farmer groups (Benin, 2007). In West Nile beekeeping was selected as a promising farm enterprise alongside with the introduction of a new breed of goats and a new groundnut variety. Table 9.1 provides a timeline of the events in West-Nile. 
Table 9.1. Timeline of events in West Nile. ${ }^{1}$

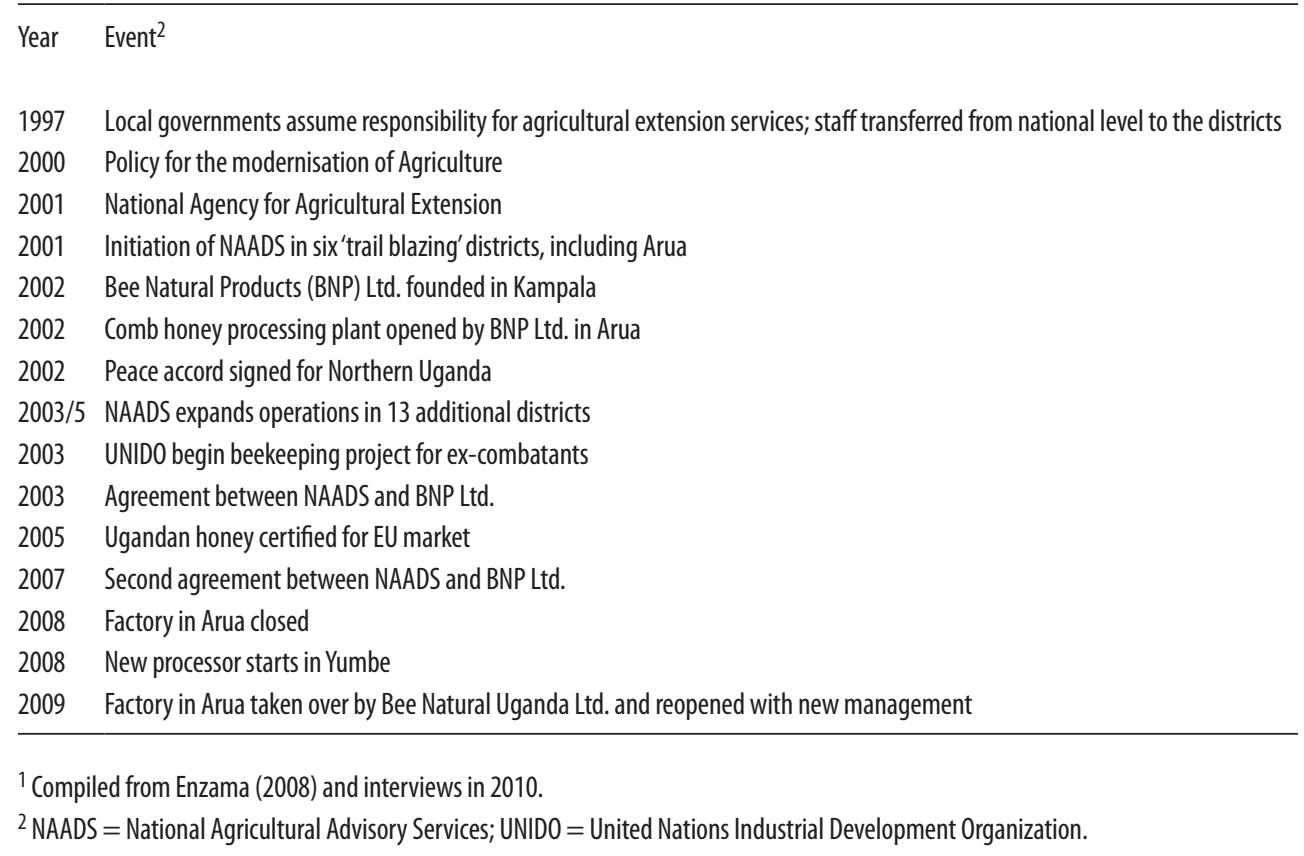

Beekeeping has since long been a traditional subsistence activity, especially in the highlands of West Nile. The activity was still rudimentary and largely unexploited as a farm enterprise. Mostly it took place in the form of gathering wild honey from caves, trees and anthills as part of collective socio-cultural activities of many communities in the region. Local self-made beehives were small and made of one piece and were often poorly sited. Wild honey gathering consisted of burning the natural colony if one suspected there to be sufficient honey, something, which disrupts or may destroy the bee colony. The honey then often contained traces of burnt materials and the smell of burnt bees and ashes. Honey was extracted from the comb by squeezing it with a cloth, without control of moisture. Others boiled the comb, altering the chemical composition of the honey. Honey was kept in small sized containers and cans. As a result productivity and quality of honey and beeswax was low and attracted low prices.

But beekeeping had considerable potential to introduce new technology, raise productivity in beekeeping and improve the quality of the honey. Firstly, there was considerable local and external demand for honey; secondly, the investment and operational costs of beekeeping is relatively low. It can thrive on marginal and infertile land that cannot support crop cultivation, as long as foliage is available. Other inputs (protective gear and equipment) can be shared with other beekeepers. As upfront costs are low, a farmer can break even within a year if good management practices 
are adopted. Beekeeping has limited vulnerability to disease and natural calamities; moreover it improves crop pollination and is an environmentally sound investment. Last but not least, it is not a physically strenuous exercise and youth as well as elderly, men as well as women can do it. It is a part time and seasonal activity where harvesting takes place twice a year.

When NAADS canvassed the selected sub-counties in 2001, there were an estimated 1,000 households scattered throughout the region regularly undertaking beekeeping activities. The formation and capacity building of farmer groups was the first challenge of institutional development. This was contracted out to NGOs. In 2001 the district government of Arua, NAADS and two NGO signed a memorandum of understanding for the purpose of formation and training of farmer groups.

Institutional change was needed and clearly associated with the introduction of new physical technologies of beekeeping, new farm level routines or practices. In addition new complementary institutional arrangements or 'social technologies' (Nelson, 2008) had to be designed to organise farmer groups and networks with other chain actors, with the purpose to impart knowledge and skills, jointly manage equipment, get access to micro-credit and eventually undertake group marketing.

The program soon ran into problems. Agricultural training institutions in Uganda did not offer course and expertise in beekeeping and related disciplines. In the whole of East Africa there was only one such institution in Tanzania. District entomologists stepped in to provide some technical assistance. NGOs had expertise and track records in capacity building in community groups and could engage farmers and provide capacity building in setting up and self-management of farmer groups, but were ill-equipped for specialist BDS in beekeeping.

Beekeeping is more developed in the relatively affluent central and western regions of Uganda. The Uganda National Apiculture Development Organization, a business interest association, draws most of its members from here. At that time, Mrs Maria Odido was its chairperson. She had taken a keen interest in the development of PMA and of NAADS and recognised their potentials. In 2002 she established a private limited company together with Mr Antonio Di Fonzo called Bee Natural Products Ltd. (BNP) in Kampala. In the same year she took samples of West Nile honey to an auction in the Netherlands where it was rated second to Brazilian honey in terms of quality.

The demand perspective for honey was generally considered rather positive both domestically and abroad. West Nile produces organic honey, which could potentially penetrate the fast growing demand for organic honey in Europe (Loon and Koekoek, 2006; cited by Enzama, 2008). In 2005 honey from Uganda was certified for export to the EU. Entering this market offered huge opportunities but also enormous challenges. After all, it implied developing a substantial agro-export chain, which would have to handle considerable volumes in order to become sustainable. 
So, if demand conditions were favourable, a chain coordinator was needed that would be capable to organise this new export chain. In 2002, BNP Ltd. made a first step in this direction by setting up a honey processing plant in West Nile, located in Arua. This plant had an installed annual capacity of 600 metric tons. BNP aimed to produce honey and beeswax finished and labelled to international standards and ready for the consumer market. But setting up a continuous supply chain of quality organic honey for a plant of 600 metric tons is quite something else than creating farmer groups to be endowed with new technology and skills to produce better quality honey.

In October 2003 BNP and NAADS signed an agreement whereby BNP would assist in implementing the action plans of beekeeping farmer groups. The goal of the agreement was to speed up the adoption of improved technology by beekeepers to increase honey productivity and sales so as to diversify sources of household cash income. At the same time, the agreement served BNP to create its own network of suppliers of comb honey. Concretely BNP was to: (1) facilitate formation and strengthening of beekeepers associations (of beekeeper groups) for organised production and collective access to inputs and product markets; (2) offer extension services for commercial beekeeping; (3) introduce new technologies and beekeeping practices, notably better yielding and long lasting bee hives and harvesting gear and equipment; and (4) to buy the comb honey produced while beekeepers would reciprocate by selling their comb honey to BNP.

The first beneficiaries were 42 beekeeper groups in Arua. Groups in other districts were later incorporated into the agreement, covering about 5 groups per sub-county out of an average of 20 groups. The cost of the contract was equivalent to $€ 40,890.00$ which was meant to cover costs of training artisans to make 'improved technology' beehives, extension service, distribution of beehives and demonstrations. This fund was managed by the NAADS secretariat.

The formation of beekeeper groups (as a social technology) was for NAADS primarily motivated by the need to reduce the costs of transferring knowledge about improved technologies and associated farm practices within the desired framework of a market for agricultural BDS. For BNP, however, the beekeeper groups were critical for the development of its own supply chain, ensuring continuous high quality supplies of honeycomb and reducing logistic and transaction costs. By investing in the relations with beekeeping groups and assisting NAADS with tasks, BNP expected to build up trust with beekeepers for future buyer-supplier relations.

Where NGOs were limited to organise farmer groups, BNP could continue imparting skills and technology, and train beekeeping groupsin joint marketing, joint management of equipment and of demonstration sites. The formation of associations of beekeeping groups was important for BNP. This higher level of self-organisation of beekeepers would reduce the complexity of supply chain management for BNP. This however turned out to be much more difficult than originally foreseen. Joint sales managed by the associations would demand a more complex and transparent management system 
of accounting for group and individual contributions. Furthermore, associations would also become a stronger party negotiating contracts with BNP. Last but not least the associations required a high level of trust among farmers and farmer groups.

The improved technology centred on the use of a new type of beehive. Under the agreement, the Kenyan Top Bar (KTB) hive was introduced and popularised in the region to replace the traditional log hives. BNP set up two apiary technology demonstration and trial sites in each of the 12 participating sub-counties to demonstrate the use of the KTB hive for improved production. BNP introduced to the use of smokers for harvesting. Producers now also wear protective gears, gloves, and gumboots during harvesting. In this way, not only the quality of honey is improved but also the quantity that is harvested from one hive rises.

At the time of the agreement in 2003, the beehives were imported from Kenya and brought in from Kampala. This was not only time consuming but also costly. At the initiative of BNP, five artisans were trained and equipped by BNP with tools and machinery to produce hives locally. As a result, in Arua alone, the trained artisans have established three workshops and employ over 30 workers. The region now no longer imports hives. Business for these workshops is set to improve with the neighbouring Sudan and Congo placing orders for hives from West Nile.

Much as the high price is conducive for the young artisans to increase their earnings from the sale of hives, many smallholders cannot afford hives. Micro-credit is still hard to access for agriculture and related activities from financial institutions. In order to cope with this financial market failure, BNP started making agreements with individual farmers to distribute beehives to them and deducting the cost from the payment for honey over a period of two to three years.

BNP advisory services involved imparting apiary management techniques and production knowledge: how to locate good apiary sites, baiting of bees and techniques of determining the readiness of the honey for harvest, how to maintain apiary site to avoid infections and threats of ants, lizards and snakes, etc. The field officers of BNP paid regular visits to the apiaries to demonstrate the skills learned in theory and for purpose of comb inspection and quality checks. In this way, BNP was able to trace and control the quality of the production process right from apiary to the factory.

A common problem in beekeeping in West Nile was the low colonisation rate of beehives, which stood at only $60 \%$. As more hives were being introduced, queen rearing became the answer to raise the colonisation rate. In 2007 the second agreement was signed between NAADs and BNP, which apart from up-scaling the previous activities now also included the setting up of demonstration sites for queen rearing. This agreement involved a total of $€ 73,293$ of which $12.8 \%$ was an in-kind contribution from BNP as part of their normal interventions and as a lead firm of the export chain. The remainder came from the NAADS programme. This activity had difficulty getting off the ground due to the lack of BNP manpower with the requisite skills. 
BNP constituted the primary link to the market: It was expected that BNP would buy all the honey from the producers. Likewise, producers were expected to sell their honey to BNP in exchange for the support offered in terms of inputs, technology, training and upgrading of products. A win-win situation was envisaged: the farmers would benefit from a ready and predictable market for their honey, reduced transaction costs, while BNP increased its assured sources of quality comb honey. This complex institutional arrangement can be classified as an informal relational contract.

Initially, farmers were happy and expectant with this arrangement because BNP was seen as a credible registered firm, with a location in the region, recognised by government and providing opportunities for acquisition of new and improved technologies and practices. However, the beekeepers were not party in the agreement between NAADS and BNP. Moreover, the agreement was silent on quality standards, price and delivery arrangements. The grading of the quality of honey was set and done by BNP at the factory and in absence of the producers. There were basically two grades of honey (A and B) according to moisture content, colour and scent. Furthermore, BNP tended to offer lower prices than other traders, which is something the company justified on the grounds of the subsidies in kind in the form of technical assistance, and implied financial costs of providing beehives with deferred re-payment.

Initially BNP paid promptly, but as the supply chain became more extensive and complex, payments delayed two weeks or more, while other travelling traders paid cash on delivery. Side selling by beekeepers increased as more traders visited Arua, attracted by its growing supply base. As side selling increased it became uneconomical for BNP to send out its truck to collect smaller quantities of honey from distant locations and effectively the spatial range of the supply chain shrank and with it the production supply base. By 2007 the factory was operating at not more than $25 \%$ of its capacity. Overhead costs rose, reducing further the ability of BNP to raise producer prices.

Clearly non-core activities had started to overwhelm BNP. Not only the number of farmer groups embracing apiculture rose rapidly, but also the number of activities undertaken by BNP to support the expansion and deepening of the honey supply base increased: from technical advice and training of beekeepers, co-financing the local production of beehives and their distribution, queen rearing and setting up the supply chain for processing and sale of honey and beeswax in domestic and export markets. With only two extension staff the quality of its service started to decline and eventually stopped in 2005 .

The company was also hit by high turnover of staff. The employees complained of poor pay and terms of service and the director of BNP accused the employees of cheating the company and not accounting for some company funds. Employees who were fired became rival traders in honey. Consistency and continuity of service delivery to the beekeepers was thus undermined. The trust which BNP had started to build up with beekeepers, rapidly eroded. In 2008 the company decided to close down the factory 
as processed volumes had become uneconomical. Later on, in 2009 the processing plant in Arua was re-opened under new ownership and management and it is set to re-develop supplier relationships and regain beekeeper's loyalty.

What were the effects of the disruption of the BNP value chain on beekeeping in West Nile in 2008? Clearly BNP could not continue to remain a de-facto monopsonist controlling the entire value chain. Beekeepers became disloyal as evidenced by rapid rise of side selling and by BNP's inability to enforce the informal institutional arrangements with local beekeepers groups. Even beekeepers, who had obtained beehives from BNP were side selling and claimed that they could not deliver honey to BNP and thereby repay their loans in kind.

Clearly, BNP suffered from own management problems as evidenced by a lack of effective costing and contracting of non-core activities with beekeepers (and with which it had no prior experiences), lack of transparent quality assessment and pricing and the inability to manage the expanding supply chain as evidenced by increasing delays in payments and declining levels of service delivery. Supplier loyalty was high at initial stages as the benefits in the form of free services were visible and highly appreciated but declined later on as prices became a contentious issue and switching to the alternative option of side selling became easier to realise as more traders visited the area.

Furthermore, other actors introduced different technologies and alternative institutional arrangements to the region. Firstly, United Nations Industrial Development Organisation (UNIDO) developed a project in West Nile to promote beekeeping, small-scale processing of honey and marketing under arm's length market arrangements for ex-combatants of defunct rebel groups. Secondly SNV, a Dutch development organisation, which focused on larger beekeepers associations and provided organisational capacity building and facilitated links with credible (but mostly non-profit) organisations providing tailor made technical, logistical, market and financial support to expand the supported association's operations. SNV has supported 127 groups in the neighbouring Moyo District and the Netherlands Embassy subsidised beehives and equipment. Thirdly, enterprising beekeepers started investing in forward integration at a small scale. By starting their own small scale processing units, they undercut BNP while benefitting from the development of the improved technologies and production services among beekeepers. One example is the company 'Bee for Life' in the nearby Yumbe district, which buys honey from some 500 beekeepers.

As BNP no longer met the advisory and technology needs of the growing number of beekeepers, the local governments in the region through the NAADS started to expand contracts to private service providers to offer supplementary advisory and technology development services to fill the gap. By end of 2004, graduates from Nyabea Training Centre in Masindi, with elementary certificates in apiculture expanded the supply of advisory services in the region. By 2007 some 37 of these 
graduates were awarded contracts to support the beekeeper groups with advisory services and technology development. The dependence on BNP as a provider of key technological services declined.

What have been the overall local development results? The sector has experienced steady increase in the number of beekeepers from about 1,000 in 2002, before the agreement, to 4,000 in 2005 and over 6,300 in 2007. Idle resources like land, unsuitable for crop cultivation, has been put to use as apiary sites. Youth, majority of whom do not own and control land, is able to participate in the industry and also elderly members of the community who were unable to engage in crop agriculture could stay active in apiculture. The industry has created dynamism in the West Nile economy. Backwards and forward linkages have been developed. The local artisans who are making beehives and tailors who make protective wears have created opportunities for raw material input dealers. Additional processors set up operations and new traders arrived. BNP has also extended the honey chain to global markets, albeit temporarily. Beekeepers have gone back to the domestic arms-length market relations due to attractive domestic prices, incomplete contracts and lack of trust.

\subsubsection{Institutional change for smallholder participation in export-agriculture in Northern Peru}

The origins of our case can be traced back a Jesuit priest Jose de Bernardi, who developed the ideas concerning the creation of the Centre for Transfer of Technologies to University graduates (CTTU). Table 9.2 presents a timeline of the main events of CTTU and its activities (Helmsing, 2009). The CTTU targeted graduates of the regional universities and provided them with the opportunity to become young entrepreneurs forming their own agro-enterprise, dedicated to the growing of a high value export crop - asparagus. The intervention logic was primarily justified on political grounds: how to prevent that frustrated university graduates join the terrorist movements and instead of 'promoters of violence' become 'promoters of peace. However, its application was primarily economic: how to form entrepreneurs and incubate their enterprises.

Crucial in the germination of his ideas was a chance encounter in 1990 between De Bernardi and the owner/manager of an innovative firm, TAL S.A. In 1991 the CTTU was created. Additional resources were subsequently obtained from a Dutch cofinancing agency, which enabled it to expand staff and actually start its activities. A first land holding was acquired on desert land to begin incubation of agro-enterprises using advanced technology and farm management methods, developed with the 'foster enterprise' (TAL S.A.). Drip irrigation technology, which was new to Peru, required a minimum scale of operation in order to be economically viable. Single person enterprises envisaged as part of the incubation process were too small. This problem could be addressed by creating a cooperative in which irrigation assets would be pooled. But since the collapse of the agrarian reform, cooperatives had a 'bad reputation. Therefore CTTU chose another collective solution well-known to its staff 
Table 9.2. Timeline of events in La Libertad, Peru. ${ }^{1}$

\begin{tabular}{|c|c|}
\hline 1990 & Principal protagonist meets leading entrepreneur: a learning alliance is formed \\
\hline 1991 & Creation of Centre for Transfer of Technology to University (CTTU) graduates \\
\hline 1993 & CEBEMO (later named CordAid) approves the (TTU project for funding (1993-1995) \\
\hline 1993 & Acquisition of the land holding'San Juan' from the CHAVIMOCHIC project ( 25 ha) \\
\hline 1993-1995 & Promotion of first cohort of (12) young entrepreneurs - Drip Irrigation Production Unit (DIPU) 'San Juan', Moche \\
\hline 1994 & CTTU itself is legally constituted as'non-profit socio-cultural association' \\
\hline 1995 & First promotion of Gravity Irrigation Producer Association (GIPA) groups (5) in Chao and Virú \\
\hline 1995 & Second promotion of (10) young entrepreneurs - DIPU'San Martin', Moche \\
\hline 1996 & CEBEM0 agreed to finance a second project phase (1996-1998) \\
\hline 1996 & Agreement with community of Paijan - CTTU acquires 100 ha of communally held desert land \\
\hline 1997 & Third promotion of (12) young entrepreneurs - DIPU'San Jose', Paijan \\
\hline 1997 & CTTU creates an agricultural enterprise 'Casuarinas', Moche \\
\hline 1998-1999 & Serious damages by heavy rains caused by 'El Niño' and a drop in asparagus yields \\
\hline 1999 & CordAid agreed to finance a third project phase (1999-2001) \\
\hline 1999 & CTTU starts a parallel integrated local development project in Paijan, financed by Action Aid \\
\hline 1999 & Fourth promotion of (10) young entrepreneurs, DIPU'San Ignacio de Loyola', Paijan \\
\hline 1999 & DIPU San Juan creates a Limited Company called'Agro San Juan SAC' \\
\hline 1999-2000 & Four new GIPA groups are formed in Paijan; two GIPAs formed 1988 close down \\
\hline 2000 & Asparagus price drops in the international market (price war initiated by China) \\
\hline 2001 & Formation of six new GIPA groups in Paijan; two GIPAs of 2000 close down \\
\hline 2000-2001 & Export boom becomes a bust: falling international prices \\
\hline 2001 & Drop in GIPAs (2) and GIPA membership (95) in Virú, Chao and Chimbote \\
\hline 2001 & Government policy to create a plural and competitive system of agricultural BDS \\
\hline 2003 & Governing board CTTU: CTTU to withdraw from credit operations \\
\hline 2003 & DIPU San Jose, Paijan creates limited company called 'Agro Lider SAP SAC' \\
\hline 2004 & $\begin{array}{l}\text { CTTU secures two government funded projects providing business development services and chain } \\
\text { coordination to contract farmers }\end{array}$ \\
\hline 2005-2006 & New model replicated among small producers and companies \\
\hline 2007 & Financial institutions accept CTTU model for group loans for export agriculture finance scheme \\
\hline
\end{tabular}

${ }^{1}$ Sources: field interviews and internal documents CTTU.

and existing in Peruvian civil law: a non-profit 'welfare organisation'. This became the Drip Irrigation Production Unit (DIPU), which legally owned the irrigation infrastructure, serving 15 to 25 one-hectare single person enterprises. The first DIPU started operations in 1995 with 12 university graduates after a long struggle to locate underground water for irrigation. It achieved spectacular yields, much higher than large-scale agro-companies in the region.

As the fame of the project spread to peasant communities in the valleys of the Department, these began to pressure the CTTU 'not to abandon them'. Resource 
conditions on peasant smallholdings, however, did not permit drip irrigation and technological constraints led to a complementary institutional adaptation. The Gravity Irrigation Producers Association (GIPA) was a new institutional arrangement created in 1995. This institutional arrangement does not own any assets but organises selected groups of young rural higher education graduates for learning, input distribution and group marketing. In the second half of the nineties a number of GIPAs were created in the valleys of Chao, Virú and Chimbote.

A major breakthrough in addressing the land constraint to incubate advanced technology enterprises (DIPUs) was the 'acquisition' of 100 hectares of desert land owned by the community of Paijan (in the North of the Department of La Libertad) on the condition that CTTU would stimulate enterprise development in DIPUs and GIPAs in the Paijan district.

Faced with market failure in the credit market, credit then became the most binding constraint. CTTU addressed this by assuming responsibility for a large loan obtained from the Canadian Counter Value Fund. The number of DIPUs and especially GIPAs increased rapidly. In order to serve the new enterprises with high yielding varieties, CTTU set up its own nursery in 1997 where it produces seedlings under controlled conditions. Seedlings were provided as a service, free of charge, to DIPU and GIPA members.

The asparagus export boom in the region received a big stimulus with completion of the CHAVIMOCHIC project. The state sold by public tender 9,000 hectares of dessert land alongside a newly constructed irrigation channel to large companies, many of which invested directly in asparagus production. As a result, the region became a leading exporter. The asparagus boom attracted also related and supporting industries and service providers (input distributors, sale and hire of farm equipment, etc.) as well as rural labour that migrated from the peasant community highlands of the Andes to work the fields in this coastal region. Within a period of five years a new regional export base developed around one single crop, asparagus.

In 1999 CTTU applied again to the Dutch co-financing agency for financial support for a third period. This third application was also successful. The number of applicants to CTTU grew, attracted by the high incomes earned in the export activities. The relative resource abundance of CTTU in those years resulted in less strict selection by CTTU of potential entrepreneurs.

In 1998-1999 the 'El Niño' phenomenon struck, causing heavy rains and flooding in the valleys, resulting in damages to irrigated fields. Crop yields declined in GIPAs in these valleys, but DIPUs situated in the desert were not affected. Before small farmers could recoup their losses, an aggressive Chinese export drive in the world market led in 2000-2001 to a fall in asparagus world prices. The number of GIPAs as well as GIPA membership declined rapidly. Members defaulted on their loans and left the CTTU 
with their accumulated debts. The growth of DIPUs also stagnated as economic prospects had declined.

The institutional change agent, CTTU, suddenly found itself in crisis. Thanks to 'bridging finance from Cordaid, CTTU could engage in extensive consultations with its principal stakeholders and producer groups. The new institutional choices made by CTTU were influenced by three main factors: (1) important changes in the broader institutional environment, notably a new agricultural policy of the Peruvian government, which created new opportunities for CTTU based on its acquired reputation; (2) the response of Peruvian export firms to the competitive challenge of China; and (3) the vision of the CTTU about its own future role.

The World Bank sponsored INCAGRO project signified an important change in Peru's agricultural policy. Its aim was to create a market for business development services for commercial agriculture, whereby private firms and NGOs provide extension services to groups of producers, which were co-financed by the Government. At the same time the Peruvian Government created so-called 'second tier' funds to finance the expansion of commercial agriculture. The INCAGRO project was a national scheme to which (independent) groups of agro-producers could apply often in association with agro-industry. Thanks to its accumulated experience and reputation, CTTU could organise groups of producers and team up with agro-industrial firms and could make several successful bids.

The second factor refers to technological innovations in transport of horticulture exports in neighbouring Chile and their adaptation to the Peruvian asparagus (the use of air controlled containers extending the fresh life of horticulture products by changing the percentage of oxygen) and the extension of this shipping service to Trujillo, Peru. Thanks to these technological innovations, the Peruvian firms succeeded to redefine their market niche by switching from preserved white asparagus to fresh green asparagus. Since then they have become world leader in fresh asparagus, leaving China to dominate the world market of preserved (canned) asparagus.

The technological innovation in production and logistics related to asparagus also made it easy to adapt these to other high value export crops. This made it possible for Peruvian firms to diversify their export crops. The new export products were annual crops (artichoke, peppers, etc.) reducing the high risks associated with investment in semi-perennials, such as asparagus. Based on prior successful collaboration with CTTU, export companies shared their learning experiences and on that basis CTTU could relatively quickly adapt training packages to the new crops.

The Government policy of financing commercial agro-export set the terms for the new contractual arrangements. Banks would provide credit against the presentation of a contract with an agro-export firm. This led to a local adaptation of a contract farming model: CTTU became a chain coordinator, providing chain coordination, agricultural extension and related business services to small producers. For small 
producers the CTTU provided 'transaction opportunities' in markets not accessible to them individually, notably in the markets for export crops, for inputs, and for credit. The risks of operating in volatile export markets were managed by means of new interlocking contractual arrangements between CTTU and smallholder, between smallholders and export companies and between smallholders and banks with CTTU as co-signatory. In this new institutional set up, CTTU became a non-profit or social enterprise with a mission to serve small producers but charging for its services.

How successful has the CTTU been in its original objectives? The results are mixed: the original plan of incubation of individual enterprises in combination with a desert land colonisation scheme, based on the DIPU model was, in the end, not successful. The chosen institutional arrangement 'froze' the incubation process. The institutional arrangements of a welfare organisation did not permit unsuccessful members to exit with compensation for their past efforts. CTTU has been most successful with the institutional model it had neither initially designed nor foreseen. This was the new GIPA model (a combination of collective action, contract farming and social enterprise services), creating 'transaction opportunities' for educated children of the 'parceleros of the agrarian land reform' and incubating their new enterprises on small plots on former irrigated estates.

CTTU's success can be explained by its capacity to adapt to changing circumstances, aided by long term funding from a 'patient' donor, a learning alliance with an innovative private firm and by having built up a reputation with large export companies. The very transformation of the regional economy created 'a critical mass', economically and politically. Economically, in so far that the geographical concentration of asparagus production attracted specialised suppliers and services to the region from which also small producers benefitted and because large firms were able to respond successfully to the competitive challenge of China. In political terms in the sense that export business leaders from the region were invited to help give shape to the new agricultural policies of the Government (INCAGRO project) and because large companies were able to lobby the Government for infrastructural improvements (roads and sea- and airport).

Since its re-engineering, the CTTU has selected more than 420 persons for its entrepreneurship and enterprise development programme. Table 9.3 gives an overview of the status in 2008 of all incubatees since 2000 . Of these, nearly $10 \%$ in that year were participating in the programme. 57 entrepreneurs were engaged in export chains coordinated by CTTU and another 60 were doing so independently from CTTU. Another 30 persons could find employment in the same sector, thanks to the competences acquired through CTTU. In almost 100 instances, CTTU was unsuccessful. The incubatees, after some time, switched back to traditional crop cultivation and farming practices. There were also three categories of what we could characterise as unsuccessful instances as people moved out of agriculture altogether, either they migrated, switched to non-agricultural occupations or social reasons explained their exit. Furthermore, a significant group of persons (11\%) existed without any information on their whereabouts. 
Table 9.3. Status in 2008 of the Centre for Transfer of Technology to University (CTTU) incubatees since 2000. ${ }^{1}$

\begin{tabular}{lcr}
\hline Status & 2008 & $\%$ \\
Currently in process of incubation & 41 & 9.7 \\
Start-up enterprise operating in chains coordinated by CTTU & 57 & 13.5 \\
Start-up enterprises operating independently in group based agro-export cultivation & 60 & 14.2 \\
Employed in the agro-export sector & 30 & 7.1 \\
Unsuccessful incubation - returned to traditional cultivation & 98 & 23.2 \\
Unsuccessful incubation - moved into non-agricultural employment & 39 & 9.2 \\
Unsuccessful incubation - rural to urban migration & 14 & 3.3 \\
Unsuccessful incubation - due to social reasons (incl. health) & 28 & 6.6 \\
Other & 9 & 2.1 \\
Without information & 47 & 11.1 \\
Total & 423 & 100.0 \\
\hline
\end{tabular}

${ }^{1}$ Source: registers CTTU, Trujillo, Peru.

In order to conclude on the performance, Table 9.4 defines 'success' and 'failure' rates. Criterion 1 is the strictest definition of success: Have incubatees become independent entrepreneurs who now operate their enterprises in agro-export crops on their own or with independently formed groups? Using this criterion only $14 \%$ of the incubatees of CTTU can be considered successful. Criterion 2 recognises that small farm enterprises face systemic market failures and need 'allies' who help overcome these. The CTTU performs this role through its coordination of the agricultural production segment of agro-export chains. In this case the success rate rises to $28 \%$. Criterion 3 has the broadest success definition. For people who fail as entrepreneurs, but who remain employed within the agro-export chains, one cannot conclude that the investment has been a waste of resources. The investments continue to yield social benefits. In this case the 'success rate' of CTTU rises to $35 \%$.

We can also look at the performance of CTTU looking at the failure side. As shown in Table 9.4, the aggregate failure rate is $42 \%$. That is to say, 4 out of every 10 persons who participated in the CTTU programmes did not form agro-export enterprises or remained active in that sector. However, only 2 in 10 reverted back to traditional farming practices. The other 2 in 10 for various reasons left the agricultural sector completely. This is a general characteristic of rural processes of change. It would most likely have happened irrespective of the CTTU intervention. In that sense it is a kind of dead weight factor that needs correction in the evaluation of the results. Taking this into account it can be concluded that the overall CTTU performance can be considered positive indeed. 
Table 9.4. Success and failure of the Centre for Transfer of Technology to University (CTTU) driven change process.

\begin{tabular}{lcc}
\hline & 2008 & $\%$ \\
Success & & \\
$\quad$ Criterion 1: independent entrepreneur (without any assistance from CTTU) & 60 & 14.2 \\
$\quad$ Criterion 2: independent entrepreneur (with or without assistance from (TTU) & 117 & 27.7 \\
$\quad$ Criterion 3: active in agro-export chains + agricultural employment & 147 & 34.8 \\
Failure & & \\
Unsuccessful incubation - return to traditional cultivation & 98 & 23.2 \\
Unsuccessful incubation - other employment (non-agricultural) & 39 & 9.2 \\
Unsuccessful incubation - rural to urban migration & 14 & 3.3 \\
Unsuccessful incubation - social factors & 28 & 6.6 \\
Aggregate rate & 179 & 42.3 \\
\hline
\end{tabular}

\subsection{Reflecting on institutional co-innovation}

What are the main commonalities among and the main differences between the two cases of co-innovation? There are at least four common elements and five main differences in the process of institutional co-innovation.

First of all, the key institution itself consisted of the rules concerning the formation of similar sized farmer groups (in practice 10-15 members). In both instances the main motivation was to achieve economies of scale in capacity building, imparting new skills and practices around a new physical technology and farm level practices. The social technology of forming groups, for group-based technical assistance, learning and experimentation, was complemented by use for group level management of joint assets (experimental stations, irrigation) and joint marketing. In both instances, change agents had to overcome market failure in input markets (notably finance, but also key inputs such as queen bees and quality seeds) in order to enable small farmers to enter the new product market. Both BNP and CTTU undertook micro finance lending to enable small farmers to acquire loans to finance the new activity. In both instances, the innovative agent nearly collapsed under this weight of these 'noncore' activities, which aimed to eliminate critical and binding resource constraints of small farmers.

Secondly, in both instances the initial institution - the farmers group for organising and managing technical assistance - has been adapted to suit the coordination needs of other economic agents. In Uganda, BNP Ltd. transformed the farmer groups into a full-fledged supply chain institution to be able to export quality honey; in Peru the institution was adapted (CTTU ceased forming DIPUs and redefined the GIPAs into a more flexible annual contract farming group operating in export chains). 
Thirdly, in both instances the new institution was interlinked with other parallel institutions in order to export high value horticultural crops: in Uganda, there were bi-lateral interlocking contracts between BNP and contact farmers for purpose of supply chain logistics and with beekeepers on distribution of new beehives and on sale of honey; in Peru, the GIPA was the basis for multi-lateral interlocking contracts between small farmer groups - CTTU on the one hand and agro-export firms and banks on the other hand. In both cases products quality standards were key to access international markets. The institutional rules on standards were neither negotiated nor independently verified but in both cases defined upfront by the dominant buyer(s) of the product: in Uganda BNP itself and in Peru the agro-export firms. In Peru there were no collective assets involved in the GIPA. In practice, beekeeper groups in West Nile also did not hold collective assets.

Fourthly, in both instances there were important power asymmetries, which influenced the direction of institutional co-innovation. In Uganda BNP was initially a monopsonist and effectively tried to turn the beekeeping groups into larger beekeeper associations as key nodes in its supply chain; in Peru the agro-export firms were much more powerful than the farmer groups as the former were vertically integrated processing firms, producing high value crops on their own large-scale farms. But in both instances the market situation strongly influences the degree to which power holders could exploit their power advantage. In Uganda, the growth of the industry attracted new rival traders and some beekeepers moved forward to expand in comb honey processing, thereby opening up new market outlets for other beekeepers, undermining the monopoly of BNP and its associated supply chain institutions. Arm's length market arrangements gradually replaced value chain based networks. In Peru the agro-export firms continued to dominate the export chains, but in global markets they were also price takers.

Having enumerated the main commonalities, let us now look at the five main differences between the two cases. First of all, the products for which new physical and social technologies needed to be developed were quite different. Asparagus growing is a full time and perennial crop, while beekeeping is a part-time seasonal activity. This has important implications for the intensity with which agents 'live' by the new institutional arrangements. In the one case these concern the primary occupation of the small farmer, while for the other they relate to a complementary seasonal and part-time activity. The relative importance of the income derived from honey was much smaller than the income generated by asparagus growing and so were the risks. Not honouring commitments with BNP had less social consequences within the beekeeper communities. In Peru poorly performing small farmers were excluded from farmer groups in subsequent rounds. Upfront entry barriers associated with the product also differed considerably. Asparagus growing required minimally one hectare of irrigated land and access to water (tube-well) and a substantial amount of working capital; in beekeeping there was hardly any entry barrier and it required relatively small cash outlays. Asparagus growing was new for most small farmers, while beekeeping was a traditional practice among many communities in West Nile. 
Secondly, there were important differences in the selection process of small farmers. In Uganda's practice any rural household could participate; only large-scale farmers were excluded. In Uganda, the selection process was primarily bureaucratic: the selection of the sub-county in which NAADS would operate. In Peru there was a clear and upfront selection of young and educated small farmers (initially urban professional university graduates, later rural young farmers and graduates of agro-technical institutes). The scale of the process was quite different: in Peru the total number of small scale farmers was less than 500 in 2008; in Uganda it involved an increase from 1,000 in 2001 to 6,500 beekeepers in 2008; in Peru the same farm level technology and the associated social technology of small farmer groups was replicated to other high value export crops (such as paprika, peppers, etc.). This was not the case in Uganda.

Thirdly, and as regards actors, there were also important differences. In Uganda, the NGOs played only a supportive role. The governmental NAADS programme was the principal driver. A commercial firm (BNP Ltd.) played a key role in creating and transforming the honey value chain adapting and thereby extending the original institutional arrangements. The company initially assumed a social entrepreneurial catalytic role but later backtracked as financial and human resource implications overwhelmed it, to continue as a purely commercial firm. In Peru the NGO (CTTU) was the principal catalyst, which had a commercial firm as its ally; in the process the NGO adapted itself to changing financial circumstances (the termination of the project subsidy from a Northern NGO donor) and became a non-profit but market oriented NGO or social enterprise.

Fourthly, government policy in Uganda, and specifically the NAADS programme, played a fundamental role in shaping the institutional co-innovation. These institutional innovations were centrally decided, designed ex-ante and in detail by public officials with strong influence of the World Bank and with the aim to create market for technical assistance and to reduce the cost of implementing the new policy. Complementary innovations were made locally, by trial and error and in a decentralised manner involving other economic agents (BNP). Later on in the process, again other agents created locally rival institutional innovations (UNIDO, SNV) and rival traders offered arm's length contracts, thereby increasing the choice for small farmers but also undermining the role of beekeeper groups in the production and marketing process. In Peru, the CTTU initiated an institutional design process in a manner of trial and error, strongly guided by the unfolding technology of irrigated high value export crops growing and adapting its own designs along the way, discontinuing the DIPU and developing new and complementary institutional arrangements as the policy environment changed favourably with the new government programme of market based technical assistance (in the form of the World Bank financed INCAGRO program) and complementary financial policy ( $2^{\text {nd }}$ tier funds for innovative SMEs and commercial small export farming). The Peruvian Government policy was not leading but provided an important tipping point in the evolutionary change process led by CTTU. 
Fifthly, there are interesting differences as regard the direction of the process. In Peru and much in contrast to established NGO doctrine and practices: economic empowerment was considered fundamental to be achieved first, and political empowerment of disenfranchised groups would come later as an outcome. It should be said that in reality no evidence of the latter was found. In Uganda, the political empowerment of small farmers in order to become a stronger market party was a central feature of the NAADS policy. Without farmer groups, small farmers would not able to become an active player in the market for technical assistance and engage private sector (and NGO) suppliers of extension services. In practice however, political empowerment also followed economic empowerment: a number of successful men and women active in beekeeping in West Nile became sub-county and district level political leaders. In Peru the process was initially heavily supply driven: the unfolding technology strongly influenced the institutional options that were conceived (the DIPU). But local social demands made CTTU to adapt its institutional arrangements by creating the GIPA. Later on the new policy environment and the market demanded greater flexibility and the GIPA was adapted and farmer groups were formed more flexibly around product specific interlinked contracts. In Uganda, institutional adaptations also occurred: the small farmer groups formed to change the rules of technical assistance were transformed into supply chain nodes with their own specific institutional arrangements. However, the growth of the industry instead of consolidating the new institutional arrangements, led to the arrival of rival institutional agents and alternative options and in the end to the demise of the BNP institutional monopoly. Side selling played a key role: in Uganda BNP contracts were informal and entry of rival agents was much easier. This stood in sharp contrast with Peru where side selling was much more difficult due to the formal contracts and considerable entry barriers in processing and exporting.

Finally, let us consider the questions formulated at the beginning of this paper. We find in both instances strong evidence in favour of institutional co-innovation in different aspects of value chain development (in physical and social technologies, organisational innovations for learning, joint marketing, contract for quality products between chain actors, with innovations in complementary markets for inputs and finance). There is in both instances 'nestedness' of institutions whereby national public institutions give room for private institutions at the level of the chain (respectively level 2 institutions and level 3 institutions as defined by Williamson). However this 'nestedness' is not always present as is shown by both cases. In Uganda the process was top down and preceded value chain development, while in Peru there was a certain degree of bottom up creation of 'nestedness' as leading entrepreneurs demanded government to support the new export agriculture with institutional innovations in extension and finance. These new public policies followed and came for CTTU at the right time.

Is there a process of 'climbing the institutional ladder' as formulated by Brousseau and Raynaud suggested, whereby locally generated institutional innovations acquire greater acceptability? In the case of Peru this was certainly the case as CTTU initiated 
institutional arrangements became accepted by agro-export firms and banks, but competition between different institutional agents may cause a fall from the institutional ladder, as happened with the institutional arrangements instituted by BNP in Uganda.

While specific innovations may be designed upfront, co-innovation of complementary institutional innovations is rarely fully designed upfront but co-innovation implies a certain degree of decentralised experimentation. There may be several reasons for this, resource constraints among the principal actors (BNP and CTTU) in the face of market failures arising from the behaviour of other agents (e.g. in credit markets). But in my view the most important constraint on designed co-innovation is situated bounded rationality'. Rarely the principal innovation protagonists can foresee all contingencies and considerable 'on the ground' experimentation is needed to ensure that all complementary and co-evolving innovations match.

\section{References}

Benin, S., Nkonya, E., Okecho, G., Pender, J., Nahdy, S., Mugarura, S., Kato, E. and Kayobyo, G., 2007. Assessing the impact of the National Agricultural Advisory Services (NAADS) on the Uganda rural livelihoods. IFPRI Working paper 00724, International Food Policy Research Institute, Washington, DC, USA.

Brousseau, E. and Raynaud, E., 2007. Climbing the hierarchical ladders of rules: the dynamics of institutional framework. Working Paper, University of Paris, Paris, France.

Chang, H.J., 2002. Breaking the mould: an institutionalist political economy alternative to neoliberal theory of the market and the state. Cambridge Journal of Economics 26: 539-559.

Chang, H.J., 2010. Institutions and economic development: theory, policy and history. Journal of Institutional Economics 7: 473-498.

Enzama, W., 2008. The quest for economic development in agrarian localities: lessons from West Nile, Uganda. Institute of Social Studies, The Hague, the Netherlands.

Evans, P., 1995. Embedded autonomy: states and industrial transformation. Princeton University press, Princeton, NJ, USA.

Gomez, G., 2008. Making markets. The institutional rise and decline of the Argentine Red de Trueque. PhD Thesis, Institute of Social Studies, The Hague, the Netherlands.

Helmsing, A.H.J., 2009. Smallholder participation in high value agro-export chains in Peru. A study of the co-evolution of technology and institutions. Paper presented at the Workshop on Globalisation and Changing Geographies of production and Innovation: Implications for Workers, Firms, Regions and Countries. November 5-7, 2009. Utrecht University, Utrecht, the Netherlands.

Hodgson, G.M., 1988. Economics and institutions. Polity Press, Cambridge, UK.

Hodgson, G.M., 2006. What are institutions? Journal of Economic Issues 40: 1-25.

Kingston, Chr. and Caballero, G., 2009. Comparing theories of institutional change. Journal of Institutional Economics 5: 151-180.

Maseland, R., 2011. How to make institutional economics better? Journal of Institutional Economics 7: 555-559. 


\section{Institutional co-innovation in value chain development}

Nelson, R.R., 2002. Bringing institutions into evolutionary growth theory. Journal of Economic Perspectives 12: 17-28.

Nelson, R.R., 2008. What enables rapid economic progress: what are needed institutions. Research Policy 37: 1-11.

Nelson, R.R. and Sampat, B.N., 2001. Making sense of institutions as a factor shaping economic performance. Journal of Economic Behaviour and Organization 44: 31-54.

North, D.C., 1990. Institutions, institutional change and economic performance. Cambridge University Press, Cambridge, UK.

North, D.C., 2005. Understanding the process of economic change. Princeton University Press, Princeton, NJ, USA.

Van Loon, M. and Koekoek, F.J., 2006. Export opportunities for African organic honey and beeswax. A survey of the markets in Germany, the United Kingdom and the Netherlands. EPOPA 2006, the Netherlands.

Williamson, O.E., 1975. Markets and hierarchies: analysis and anti-trust implications: a study in the economics of internal organization. Free Press, New York, NY, USA.

Williamson, O.E., 2000. The new institutional economics: taking stock, looking ahead. Journal of Economic Literature 38: 595-613. 
